\title{
Effect of climate on Enteric Fever incidence in Ahmedabad, India
}

\author{
Veena Iyer ${ }^{1}$, Ayushi Sharma ${ }^{1}$, Susanna Cottagiri Abraham ${ }^{\mathbf{1}}$, Divya Nair $\mathrm{H}^{\mathbf{1}}$, Bhavin Solanki $^{2}$, \\ Dileep Mavalankar ${ }^{1}$ \\ ${ }^{1}$ Indian Institute of Public Health, Gandhinagar, Gandhinagar, India, ${ }^{2}$ Ahmedabad Municipal Corporation, Ahmedabad, India
}

Objective

This study is an attempt to explore the relationship of EF incidence with climate variables and ENSO events in the seventh most populous city in India.

\section{Introduction}

Enteric fever (EF) is a grave systemic infection, which has been controlled quite effectively in developed countries, but con tinues to be a grave public health concern for India. Environmental drivers such as rainfall, temperature, relative humidity and El NiñoSouthern Oscillations (ENSO) are known to influence the transmission of Salmonella typhi and paratyphi. India possesses the largest population burden of EF, yet very few studies have explored its climatic associations.

\section{Methods}

We analyzed address-confirmed widal positive, monthly EF cases reported by Ahmedabad Municipal Corporation and local climate data recorded by the Meteorology Office from 1986-2017. EF incidence trend in the city was cross validated using EF monthly reports from one large public hospital and from private reports. We also collected data for Temperature, Humidity and Rainfall from Meteorological Centre of Ahmedabad, population data from Census department, and identified IOD and ENSO events from National Oceanic and Atmospheric Administration (NOAA) for the same period.

\section{Results}

Our study recorded 29,808 Widal positive cases for 32 years. EF incidence trend over last 32 years showed a decadal pattern. Initial study period (1986-1995) showed higher and erratic case rates, while cases were more restrained during the last decade (19952005), although a steady rise is persisting. We also observed a consistent rise in EF cases in the last 8 years (Fig 1).

Analysis of annual pattern of monthly-normalized EF cases revealed a bimodal distribution of peaks, in the month of June and September. Peaks of EF cases showed a lag and lead of one month with Tmax and Tmin. The first EF peak in June lagged the Tmax peak in May by a month and the second EF peak in September led the Tmax peak in October by a month. The second peak of EF cases in September coincided with the peak humidity in the same month. The dip between the two EF peaks coincided with maximum rainfall peak in July (Fig 2 a,b,c). Spearman's rank correlation showed a small positive but significant correlation between monthly EF case rates and climate variables (Tab 1). A Poisson model showed significant but weak association between EF incidence and all climate variables - Tmin, RH and Rainfall. In our study T max had the strongest association with EF cases, wherein an increase of one case was accompanied by a $0.1^{\circ} \mathrm{C}$ increase of the Tmax (Tab 2).

Over the 32 years, there were 4 strong and 4 moderate El Nino years, 5 strong and 2 moderate La Nina years and 17 neutral years. Figure 3 shows that except for the two El Nino years which coincided with positive IOD events, the remaining six El Nino years experienced a subdued rainfall. Six out of seven La Nina years experienced high rainfall. The early El Nino events of 1986, 1987, 1991 and the most recent one of 2015 exhibit a trend of low rainfall and high cases. This trend is diluted in the middle El Nino years, 1994, 1997, 2002 and 2009 showing high and low rainfall and relatively lesser annual case rates. Although the highest case rate was recorded in a La Nina year - 59/100,000 in 1988, average case rates were highest for El Nino years (25.5), lower for La Nina (20.5) and lowest for Neutral years (17.6). However, we were unable to establish any statistical significance between average $\mathrm{EF}$ case rates during each of these periods. A spearman correlation between EF cases and rainfall was small but significant for El Nino $\left(r_{S}=0.35, p=0.001\right)$ and for neutral years $\left(r_{S}=0.20, p=0.004\right)$, but not for La Nina years. A repeated measures ANOVA

SDS Annual Conference Proceedings 2019. This is an Open Access article distributed under the terms of the Creative Commons AttributionNoncommercial 4.0 Unported License (http://creativecommons.org/licenses/by-nc/3.0/), permitting all non-commercial use, distribution, and reproduction in any medium, provided the original work is properly cited. 
analysis showed no significant difference in average EF cases during the three ENSO categories, however visual profile plot (Fig 4) of estimated marginal monthly means over the year showed distinct differences - early rise and peaking of cases in the El Nino and La Nina years, and a much more restrained rise without conspicuous peaks in Neutral years.

The 2 positive IOD events that occurred along with the strong El Nino events in 1994 and 1997 may have led to lowering of case rates during El Nino years, and thus the lack of a significant increase in EF incidence rates. But this could also be due to the fact that our analysis, unlike a time series analysis, has used an El Nino year as a variable, which does not accommodate the fact that El Nino does not run by a calendar year. We were unable to conduct a geospatial analysis which may have better correlated our data with temperature and rainfall intensity during the three ENSO phases in our region. Uneven development of urban infrastructure would also influence rates of illness. Furthermore, the cases reported to the epidemic cell were based on Slide and/or Tube Widal positive tests which is considered a poor diagnostic test. Despite these numerous and at times opposing factors influencing trends of EF, the upswing in case incidence rate early in the El Nino and La Nina years, when the weather is still balmy and water shortages haven't yet begun in the city, merits deeper investigation.

\section{Conclusions}

Future control strategies for EF need to consider the influence of local environment, geographical climate variation and seas onal patterns. This relationship between ENSO events and EF cases needs to be investigated with larger and longer data sets from different cities and towns in the sub-continent. One of the limitation of our study is we need longer and larger, spatially distributed dataset of EF incidences to associate it better with climate phenomena.

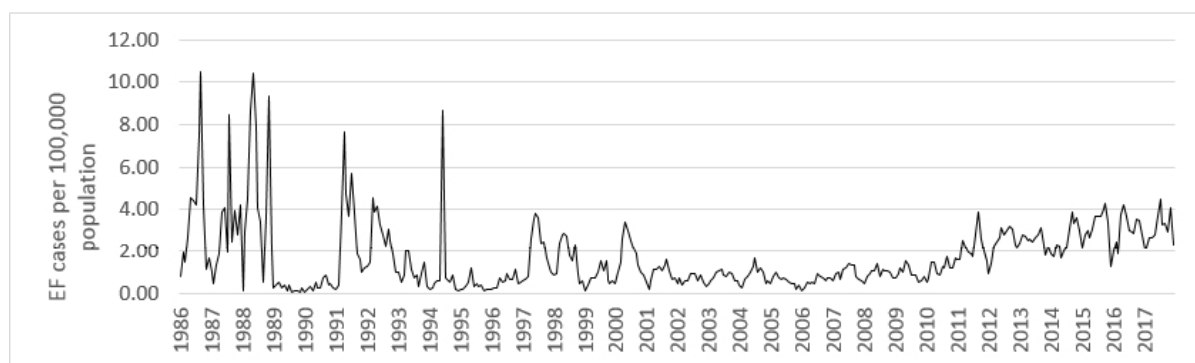

Figure 1. Inter-annual variability of EF cases normalized by per 100,000 population in the city of Ahmedabad from 1986-2017.
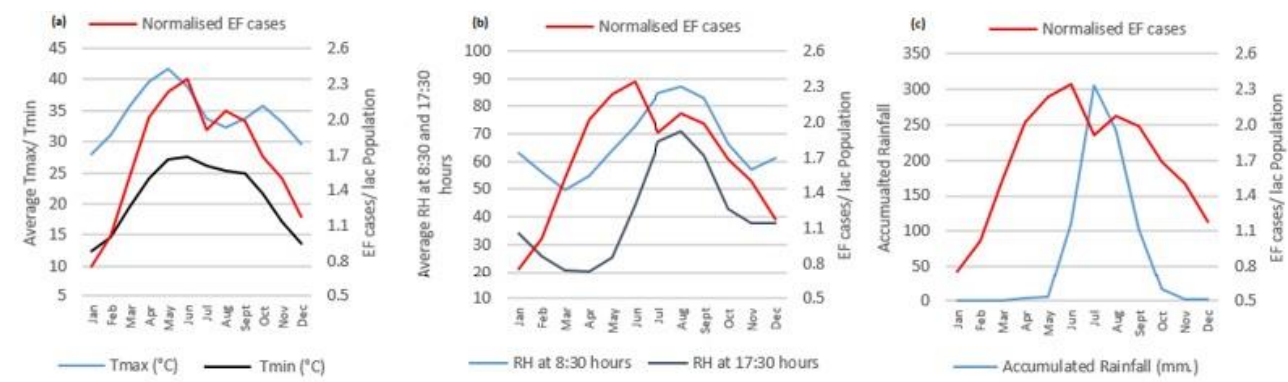

Figure 2. Monthly variability of EF case rates with (a) Maximum (Tmax) and Minimum temperatures (Tmin), (b) Relative Humidity (RH) at 8.30 and $17.30 \mathrm{hrs,} \mathrm{and} \mathrm{(c)} \mathrm{accumulated} \mathrm{rainfall,} \mathrm{in} \mathrm{Ahmedabad}$ 


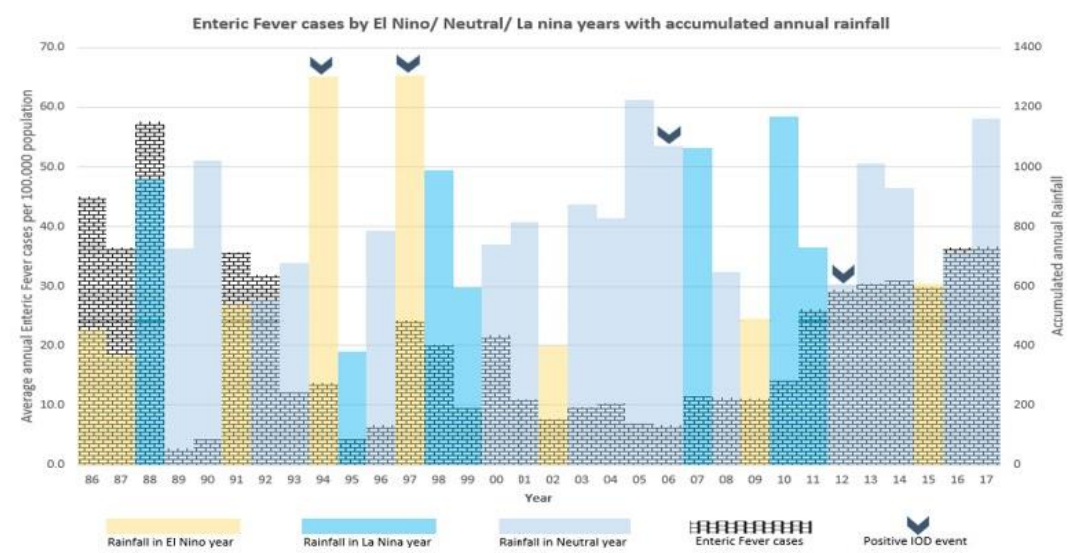

Figure 3. Trend of Enteric fever incidence by El Nino, Neutral and La Nina years with accumulated annual rainfall over the study period (1986-2017)
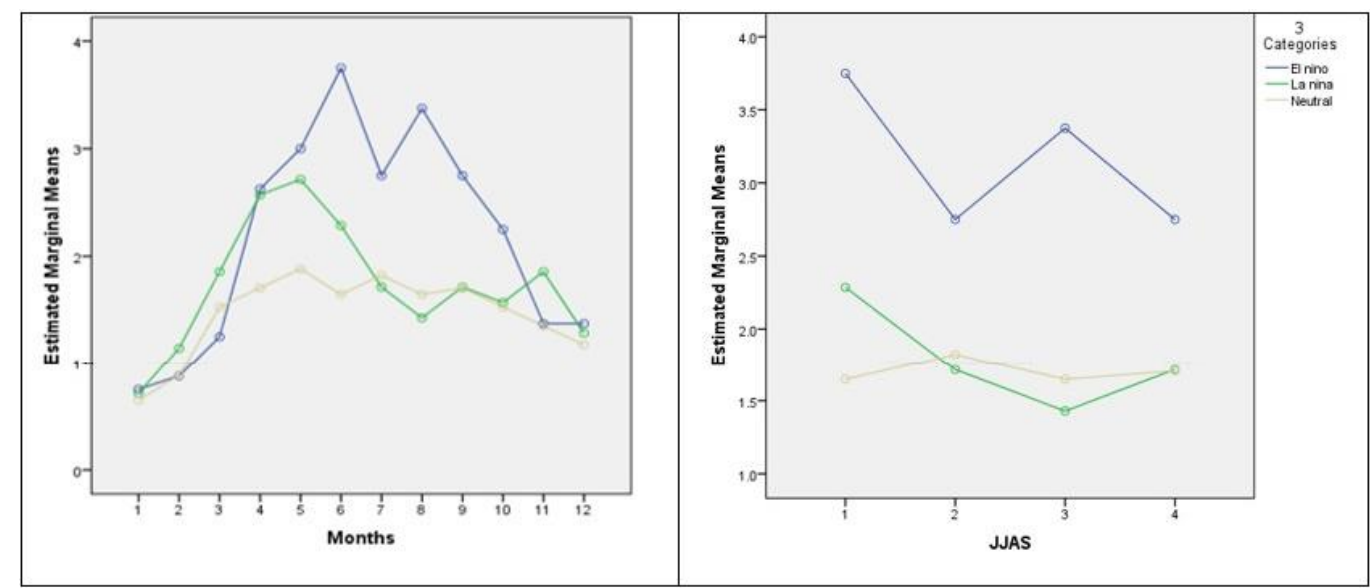

Figure 4. Profile plot of estimated marginal means of (a) monthly EF incidence (b) EF incidence in JJAS window (June, July, August and September) across El Nino, La Nina and Neutral years

Table 1. Spearman Rank Correlation (rs) between monthly average EF normalized case rates and monthly averages of weather variables 1986-2017

\begin{tabular}{|c|c||c|}
\hline Weather Variables & rs & p- value (0.01 level) \\
\hline Tmax & .279 & .000 \\
\hline Tmin & .341 & .000 \\
\hline \hline RH at $8: 30 \mathrm{hrs}$ & .186 & .000 \\
\hline RH at $17: 30 \mathrm{hrs}$ & .134 & .000 \\
\hline Accumulated Rainfall & .188 & .000 \\
\hline
\end{tabular}

Table 2. Association of climate variables and EF cases in a Association of climate variables and EF cases in a Poisson model

\begin{tabular}{|c|c|c|c|c|}
\hline Dependent variable- EF cases & IRR & Std Error & P-value & 95\% C.I. \\
\hline \hline Tmax & 1.1061 & .00637 & 0.000 & {$[1.09-1.11]$} \\
\hline Tmin & 0.9693 & .00459 & 0.000 \\
\hline
\end{tabular}




\section{OJPHI}

ISDS 2019 Conference Abstracts

SDS

TMTERNATIONAL SOCIETH

\begin{tabular}{|c|c|c|c|c|}
\hline RH at 08:30 Hours & 1.0089 & .00139 & 0.000 & [1.01 -- 1.01] \\
\hline RH at 17:30 Hours & 1.0087 & .00110 & 0.000 & [1.01 -- 1.01] \\
\hline Av. Accumulated Rainfall & 1.0002 & .00006 & 0.013 & [1.00 -- 1.00] \\
\hline
\end{tabular}

LR chi2 $(5)=2086.49 ;$ Prob $>$ chi2 $=0.0000 ;$ Log likelihood $=-8937.7701 ;$ Pseudo R2 = 0.1045 